\author{
J.-C. Devaud \\ M. M. Berger \\ A. Pannatier \\ P. Marques-Vidal \\ L. Tappy \\ N. Rodondi \\ R. Chiolero \\ P. Voirol
}

\section{Hypertriglyceridemia: a potential side effect of propofol sedation in critical illness}

Received: 27 February 2012

Accepted: 23 August 2012

Published online: 28 September 2012

(C) Copyright jointly held by Springer and ESICM 2012

Preliminary results were presented at the 30th International Symposium on Intensive Care and Emergency Medicine, Bruxelles, 9-12 March 2010.

J.-C. Devaud and M. M. Berger contributed equally.

J.-C. Devaud · A. Pannatier · P. Voirol Service of Pharmacy, Lausanne University Hospital, Lausanne, Switzerland

J.-C. Devaud

e-mail: jean-christophe.devaud@ chuv.ch

J.-C. Devaud · A. Pannatier · P. Voirol School of Pharmaceutical Sciences, University of Geneva and University of Lausanne, Geneva, Switzerland

M. M. Berger $(\bowtie) \cdot R$. Chiolero Service of Adult Intensive Care Medicine and Burns, Lausanne University Hospital, 1011 Lausanne, Switzerland

e-mail: Mette.Berger@chuv.ch

P. Marques-Vidal

University Institute of Social and Preventive Medicine, University of Lausanne,

Lausanne, Switzerland

\section{Tappy}

Department of Physiology, University of Lausanne, Lausanne, Switzerland

\section{N. Rodondi}

Department of Ambulatory Care and Community Medicine, University of

Lausanne, Lausanne, Switzerland

Present Address:

N. Rodondi

Department of General Internal Medicine Inselspital, Bern University Hospital, Bern, Switzerland

Abstract Purpose: Hypertriglyceridemia (hyperTG) is common among intensive care unit (ICU) patients, but knowledge about hyperTG risk factors is scarce. The present study aims to identify risk factors favoring its development in patients requiring prolonged ICU treatment. Methods: Prospective observational study in the medicosurgical ICU of a university teaching hospital. All consecutive patients staying $\geq 4$ days were enrolled.

Potential risk factors were recorded: pathology, energy intake, amount and type of nutritional lipids, intake of propofol, glucose intake, laboratory parameters, and drugs. Triglyceride (TG) levels were assessed three times weekly. Statistics was based on twoway analysis of variance (ANOVA) and linear regression with potential risk factors. Results: Out of 1,301 consecutive admissions, 220 patients were eligible, of whom 99 (45\%) presented hyperTG (triglycerides $>2 \mathrm{mmol} / \mathrm{L}$ ). HyperTG patients were younger, heavier, with more brain injury and multiple trauma. Intake of propofol $(\mathrm{mg} / \mathrm{kg} / \mathrm{h})$ and lipids' propofol had the highest correlation with plasma TG $\left(r^{2}=0.28\right.$ and 0.26 , respectively, both $p<0.001)$. Infection and inflammation were associated with development of hyperTG [C-reactive protein (CRP), $\left.r^{2}=0.19, p=0.004\right]$. No strong association could be found with nutritional lipids or other risk factors. Outcome was similar in normo- and hyperTG patients. Conclusions: HyperTG is frequent in the ICU but is not associated with adverse outcome. Propofol and accompanying lipid emulsion are the strongest risk factors. Our results suggest that plasma TG should be monitored at least twice weekly in patients on propofol. The clinical consequences of propofol-related hyperTG should be investigated in further studies.

Keywords Hypertriglyceridemia . ICU · Nutrition · Propofol · Sedation · Lipid metabolism 


\section{Introduction}

Hypertriglyceridemia (hyperTG) is a common metabolic complication in critical illness $[1,2]$, but data on its incidence, risk factors, and impact on outcome are scarce. The main causes of hyperTG are either genetic or associated with secondary pathology such as pancreatitis [3], sepsis [4], obesity [5], liver failure [6, 7], chronic renal failure [2, 6, 8], alcohol consumption [9] or type 2 diabetes $[10,11]$. The type of illness influences the lipid profile, the magnitude of the changes being proportional to the severity of the disease [12]; patients with infections are particularly prone. Despite unclear multifactorial etiology, high lipid levels are considered as a source of complications in intensive care unit (ICU) patients [2, 6, $8]$ and should be prevented.

Since the mid 1980s, overfeeding has been identified as a potential cause of multiple metabolic disorders. The European Society for Clinical Nutrition and Metabolism (ESPEN) guidelines recommend a daily energy intake of $25-30 \mathrm{kcal} / \mathrm{kg} / \mathrm{day}$ in medical and surgical ICU patients, and even less in the early phase [13]; daily fat intake should not exceed $0.7-1.5 \mathrm{~g} / \mathrm{kg}$ to prevent fat overload [13]. Similarly, exceeding a cumulative glucose intake of $5 \mathrm{~g} / \mathrm{kg} /$ day should be avoided to prevent de novo lipogenesis [13]. Despite these recommendations, a multicenter study reported a $33 \%$ incidence of hyperTG, defined as plasma triglycerides (TG) $>3 \mathrm{mmol} / \mathrm{L}$, among hospitalized patients receiving a parenteral daily fat intake of $0.83 \pm 0.37 \mathrm{~g} / \mathrm{kg}$ [8]. The type of lipid also influences TG levels: medium-chain triglycerides (MCT) and omega3 lipid emulsions are alternatives to long-chain triglycerides (LCT) [6, 7], even if the metabolic advantages compared with LCT emulsions remain debated [14]. Contrary to parenteral fat intake, enteral fat has rarely been associated with hyperTG [15]. Critically ill patients frequently require sedation. One of the most popular drugs is propofol, which is emulsified in lipid solutions. Some small studies suggest that high doses of propofol may play a key role in hyperTG [1,16]. Apart from feeding and propofol, several drugs influence lipid levels: statins [5] and insulin $[2,10]$ decrease TG levels, while heparin $[17$, 18], $\beta$-adrenergic catecholamines [19], and corticosteroids [2] have been shown to induce hyperTG.

The present study aims to determine the prevalence, severity, and risk factors of hyperTG in a population of critically ill patients in order to generate clinical etiological hypotheses and determine whether TG should be monitored in the ICU.

\section{Patients and methods}

This prospective observational study, approved by the ethic committee of the Vaud Canton, was conducted over a 7-month period (March-October 2009) in a 32-bed adult mixed ICU. Individual consent was waived as the lipid profile monitoring was an integral part of the ICU nutrition protocol [blood sampling three times weekly at 6 am for determination of TG levels and one time weekly for cholesterol, high-density lipoprotein (HDL)-cholesterol, C-reactive protein (CRP), albumin, and transthyretin]. The inclusion criterion was ICU stay $\geq 4$ days. Exclusion criteria were: only one determination of TG during the stay, and patients on oral feeding. Hypertriglyceridemia was defined as plasma TG level $>2 \mathrm{mmol} / \mathrm{L}$ [20], severe hyperTG being defined as TG $>5 \mathrm{mmol} / \mathrm{L}$. Patients were allocated to two groups according to peak TG level: normo- or hyperTG groups. The patients were classified according to predefined diagnostic groups, i.e., sepsis (severe sepsis and septic shock [21] on admission or at time of hyperTG), acute pancreatitis, diabetes (type 1 and 2 ), chronic renal failure, and use of statins before and during hospitalization with specification of preexisting dyslipidemia. The control group was constituted by patients without these pathologies.

Data were extracted from the the clinical information system (CIS; MetaVision ${ }^{\circledR}$ iMDSoft, version 5.45.5403; Tel Aviv, Israel), which is customized to provide detailed composition and quantities of the enteral and parenteral feeding solutions including the respective amount of LCT and MCT [22]. The nonnutritional substrate intakes were also integrated in the computations, whether coming from glucose $5 \%$ or the propofol lipid emulsions. The cumulative energy intake included nutritional (i.e., enteral = $\mathrm{EN}$, parenteral nutrition $=\mathrm{PN}$ ) and nonnutritional energy intake (i.e., glucose or lipid vehicle).

Patient data included age, admission weight, ideal body weight (IBW), body mass index (BMI), type of admission (surgical or medical), diagnosis, and mortality (ICU and hospital). Recorded medications included statins (type and dose), heparin, insulin, catecholamines, corticosteroids (hydrocortisone equivalents), and propofol $(\mathrm{mg} /$ day and $\mathrm{mg} / \mathrm{kg} / \mathrm{h})$. Propofol is delivered under three forms: $2 \%$ solution for continuous sedation (Disopri$\operatorname{van}^{\circledR}$, Astra Zeneca, Zug, Switzerland; Propofol MCT Fresenius $^{\circledR}$, Fresenius Kabi, Oberdorf, Switzerland) and $1 \%$ solution for short procedures (Disoprivan ${ }^{\circledR}$ ). The differences in fat content are integrated in the CIS.

All plasma TG values were recorded to enable the calculation of "delta-TG" (the difference between the lowest and highest TG values), including in normoTG patients; the delta-TG value hence differs from the peak value. Only the highest TG value was considered for the analysis of the temporal relationship with specific risk factors.

Laboratory data included alanine aminotransferase (ALT), aspartate aminotransferase (AST), albumin, pancreatic amylase, direct bilirubin, creatinine, gammaglutamyl transpeptidase ( $\gamma$-GT), glycemia, lipase, alkaline phosphatase, procalcitonin, CRP, thromboplastin time, 
and urea. Triglycerides, cholesterol, and HDL-cholesterol were analyzed as independent variables.

\section{Clinical management}

The ICU's feeding protocol recommends an energy target of 25 to $30 \mathrm{kcal} / \mathrm{kg} /$ day for medical and surgical conditions, respectively (with downregulation in elderly and obese) and indirect calorimetry after 1 week [23]. Continuous EN is encouraged, PN being limited to gastrointestinal failure; all feeding solutions contained either MCT/LCT mixtures or structured lipids (no fish oil). The sedation protocol based on the recommendations of the European Society of Intensive Care Medicine discourages use of high-dose propofol $(>4 \mathrm{mg} / \mathrm{kg} / \mathrm{h})$ while integrating daily sedation pauses. The ICU glucose control protocol is nurse driven and aims at blood glucose values between 6 and $8 \mathrm{mmol} / \mathrm{L}$ (determined by blood gas analyzer).

\section{Analytical methods}

Enzymatic methods were used to determine triglycerides (GPO-PAP), cholesterol (CHOD-PAP), and HDL-cholesterol (CHOD-PAP, HOMOGENE PEG). For other determinations, standards methods were used; the laboratory is ISO certified.

\section{Statistical analysis}

Results are expressed as median and interquartile range or as number of subjects and percentage, as well as mean \pm standard error of the mean (SEM) in Fig. 1. Variables were tested for normality, and TG values were found to be nonnormally distributed; therefore, $\log$ values were used for further analysis. The factors associated with hyperTG were further analyzed using simple and multiple linear regressions. The groups of patients at risk were compared post hoc with the control group using Dunnett's test. The odds ratios for hyperTG and the $95 \%$ confidence intervals were calculated using the method described by Armitage and Berry [24]. The statistical packages used were JMP V8.1 (SAS Institute, Cary, NC, USA) and R (R Foundation, version 2.15.1) open-source software. Statistical significance was considered at the level $p<0.05$.

\section{Results}

During the study period, 1,301 patients were admitted to the ICU, of whom 308 (23.7 \%) were eligible for the study; 88 patients were excluded, due to eating regular meals
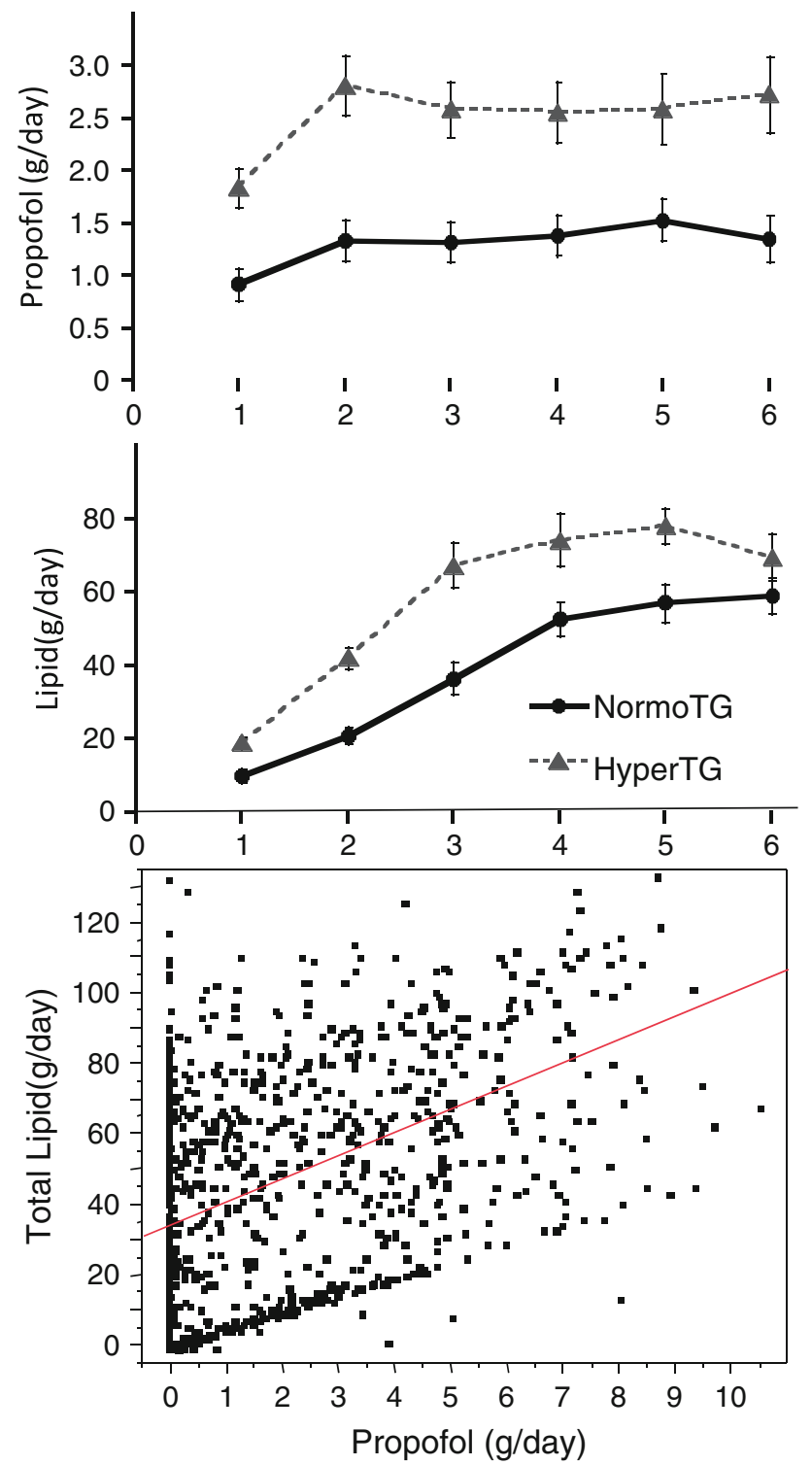

Fig. 1 Evolution of propofol and total lipid delivery during the first 6 days before the peak TG value, which occurred as a median on day 7 in normo- and hyperTG patients. The lower box shows the significant relationship existing between the propofol dose/day and the lipid dose/day

$(n=50)$, or having only one TG determination $(n=38)$ and 38 patients with only one TG determination.

The clinical characteristics of the 220 patients are summarized in Table 1. All patients required mechanical ventilation, and stayed for 10.4 days as a median in the ICU. Ninety-nine patients $(45 \%)$ developed hyperTG. The hyperTG patients were younger, had lower Simplified Acute Physiology Score II (SAPS II) scores, and stayed longer in the ICU, while mortality did not differ from normoTG. The pathologies were unevenly distributed, with more cardiac pathologies and less trauma in the 


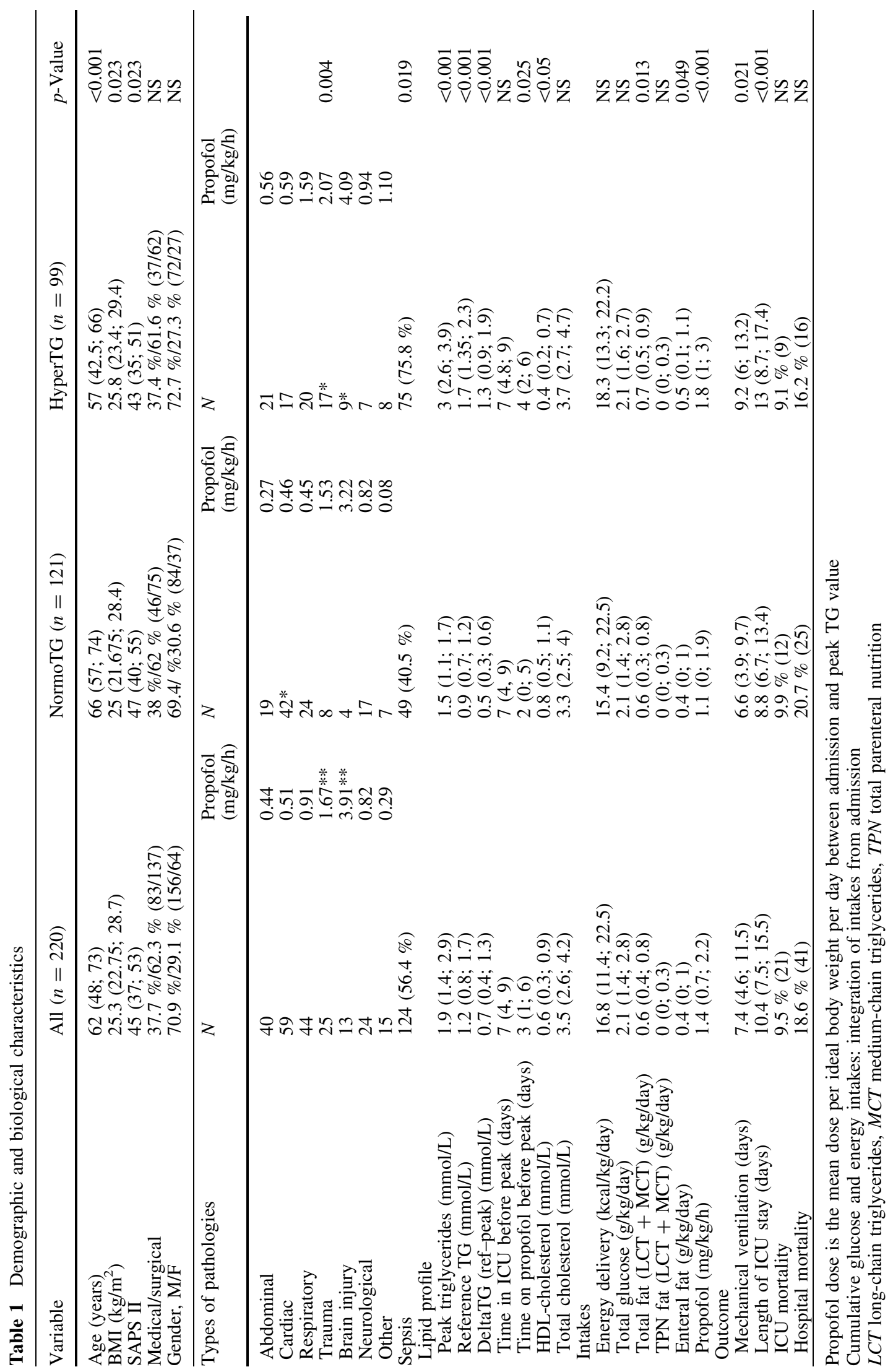


normoTG group $(p=0.04)$. Among the predefined risk categories, those poorly represented were the following $(n=11)$ : diabetes $(n=7)$, renal failure $(n=3)$, and pancreatitis $(n=1)$. Septic patients $(n=124)$ were observed in all diagnostic categories and were overrepresented in the hyperTG group $(n=75 ; 76 \%)$. Altogether 70 patients received statins either before or during their stay, 12 for dyslipidemia, 11 after acute myocardial infarction, and the others for unclear reasons.

\section{Feeding}

Twenty-four hours before the peak TG value, 136 patients $(61.8 \%)$ were under EN, $36(16.4 \%)$ were under PN, $29(13.2 \%)$ were receiving combined nutrition (i.e. $\mathrm{EN}+\mathrm{PN}$ ), and 19 were unfed. Energy intakes were on the hypocaloric side (median $16.8 \mathrm{kcal} / \mathrm{kg} / \mathrm{day}$ ). The hyperTG group received significantly more fat, while remaining within recommended ranges; energy and glucose intakes did not differ. The higher fat load in the hyperTG group resulted mainly from propofol fat.

\section{Plasma triglycerides}

TG values varied during the stay in all patients, but varied significantly more in those patients developing hyperTG.

Table 2 Correlation between selected daily parameters and peak triglyceride concentration

\begin{tabular}{|c|c|c|}
\hline Parameter term & $\begin{array}{l}\text { Pearson's } \\
\text { coefficient } \\
\left(r^{2}\right)\end{array}$ & Significance \\
\hline Propofol (mg/kg/h) & 0.28 & $<0.001$ \\
\hline Lipids from propofol (g/kg/day) & 0.26 & $<0.001$ \\
\hline CRP (mg/L) & 0.19 & 0.004 \\
\hline Total lipid intake (g/kg/day) & 0.14 & 0.024 \\
\hline $\begin{array}{l}\text { Cumulative glucose intake } \\
\text { (g/day) }\end{array}$ & 0.12 & NS \\
\hline $\begin{array}{l}\text { Cumulative glucose intake } \\
\text { (g/kg/day) }\end{array}$ & 0.11 & NS \\
\hline $\begin{array}{l}\text { Cumulative energy intake } \\
\text { (kcal/kg/day) }\end{array}$ & 0.09 & NS \\
\hline $\begin{array}{l}\text { LCT + MCT parenteral lipids } \\
\text { (g/kg/day) }\end{array}$ & 0.07 & NS \\
\hline Total LCT intake (g/kg/day) & 0.04 & NS \\
\hline $\begin{array}{l}\text { LCT + MCT enteral lipids } \\
\text { (g/kg/day) }\end{array}$ & 0.04 & NS \\
\hline Insulin dose (UI/24 h) & 0.02 & NS \\
\hline
\end{tabular}

Propofol dose is the mean dose per ideal body weight per day between admission and peak TG value

Cumulative glucose and energy intakes: integration of intakes from admission

LCT long-chain triglycerides, $M C T$ medium-chain triglycerides, $T P N$ total parenteral nutrition
The latter patients started with higher TG reference values, although the majority of these values were within normal ranges.

HyperTG occurred after 7 days as a median, and after 4 days on higher-dose propofol. Figure 1 shows the significant differences in propofol delivery between the two groups, causing a significantly larger fat delivery (daily propofol and fat dose: $r^{2}=0.222, p<0.0001$ ).

While total cholesterol did not differ significantly, HDL-cholesterol was lower in the hyperTG patients $(0.46 \pm 0.30$ versus $0.79 \pm 0.37 \mathrm{mmol} / \mathrm{L}, p<0.0001)$. Low total and HDL-cholesterol were both associated with hospital mortality $(p<0.05)$.

\section{Pathologies and drugs}

No significant relationship between comedications (insulin, heparin, catecholamines, corticosteroids, or other drugs) and TG levels was observed.

Among patients on statins, $26(37.1 \%)$ developed hyperTG versus $48.7 \%$ in those not receiving statins $(p=0.108$, NS). Patients on statins received less propofol than those without. They presented significantly fewer infections (41.4 versus $63.3 \% p=0.0023$ ) but no difference in mortality ( 9 versus $10 \%$ ICU mortality).

Table 2 summarizes the results of the single regression analysis between TG levels and the various risk factors. Correlation between plasma TG and total cholesterol was fair $\left(r^{2}=0.41, p<0.001\right)$.

Infection, inflammation (CRP), and propofol were significantly associated with hyperTG, by both single and multiple regressions (Table 3); sepsis was highly significantly associated with this metabolic alteration.

Propofol intake

Altogether 144 patients $(65.5 \%)$ received propofol, ranging from 0.04 to $5.83 \mathrm{mg} / \mathrm{IBW} / \mathrm{h}$ before their peak TG value. Patients with brain injury and multiple trauma received significantly higher doses of propofol (Table 1). A strong association between TG levels and propofol dose $(\mathrm{mg} / \mathrm{kg} / \mathrm{h})$ and the propofol lipid vehicle was observed $\left(r^{2}=0.28\right.$ and 0.26 , respectively, $\left.p<0.001\right)$. The median dose of propofol associated with hyperTG was $2.04 \mathrm{mg} / \mathrm{kg} / \mathrm{h}$. The magnitude of the TG increase (deltaTG) was influenced by the cumulated dose of propofol before the peak $\left(r^{2}=0.038, p=0.0037\right)$, the propofol dose $/ \mathrm{kg} / \mathrm{h}\left(r^{2}=0.061, p=0.0002\right)$, but less by number of days on propofol before the peak $\left(r^{2}=0.020\right.$, $p=0.034)$ or lipid dose $\left(r^{2}=0.027, p=0.013\right)$.

Total cholesterol and HDL-cholesterol levels were unaffected by the propofol dose. 
Table 3 Plasma triglyceride values and propofol doses of the different diagnostic categories

\begin{tabular}{llllll}
\hline & $\begin{array}{l}\text { Triglyceridemia } \\
(\mathrm{mmol} / \mathrm{L})\end{array}$ & $\begin{array}{l}\text { Median propofol } \\
\text { dose }(\mathrm{mg} / \mathrm{kg} / \mathrm{h})\end{array}$ & All $(n=220)$ & $\begin{array}{l}\text { NormoTG patients } \\
(n=121)\end{array}$ & $\begin{array}{l}\text { Odds ratio } \\
(95 \% \mathrm{CI})\end{array}$ \\
\hline Control group & $1.6(1.3 ; 2.3)$ & $0.8(0.2 ; 1.7)$ & 73 & 50 & $0.4(0.2-0.8)$ \\
Other groups at risk & $1.4(1.2 ; 1.6)$ & $0.3(0 ; 0.8)$ & 11 & 10 & $0.1(0-0.9)$ \\
Dyslipidemia & $1.2(1.1 ; 1.5)$ & $0.6(0.1 ; 0.9)$ & 12 & 12 & NA \\
Sepsis & $2.4(1.7 ; 3.4)^{\mathrm{a}}$ & $0.9(0.1 ; 2)$ & 124 & 49 & $4.6(2.5-8.2)$ \\
\hline
\end{tabular}

Results presented as median (interquartile range)

Other groups at risk are composed of diabetes mellitus, chronic renal failure, and pancreatitis

${ }^{a}$ Values significantly different from the control group $(p<0.001)$

Fig. 2 Example of plasma triglyceride evolution with the cumulated daily dose of the different lipid types over time ( $E N$ enteral nutrition, $P N$ parenteral nutrition). The total daily propofol dose (dashed line, hyperTG reference). In this case, events prior to day 8 (highest TG peak) were considered for analysis

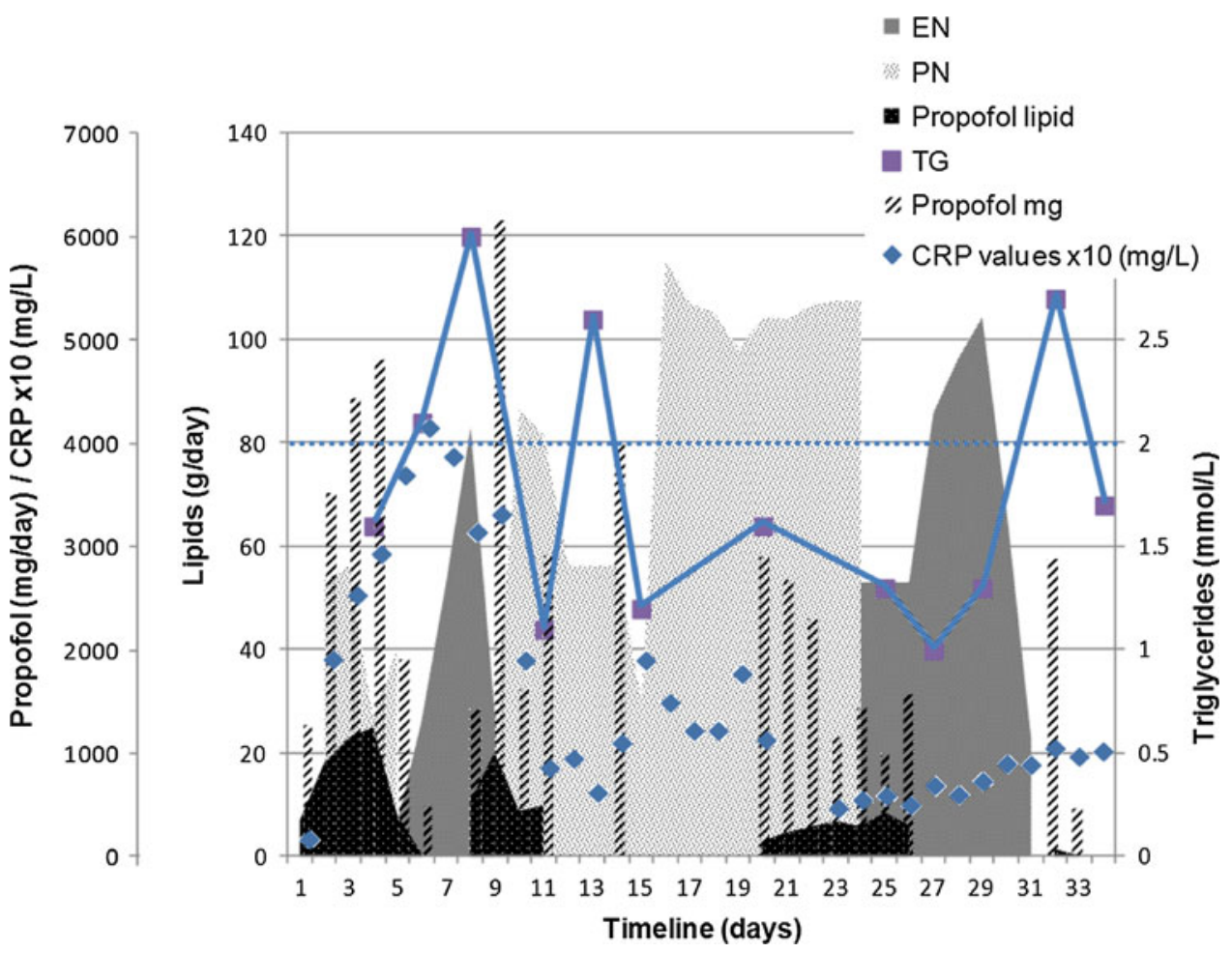

\section{Lipid intake}

Fat from feeding $(\mathrm{EN}+\mathrm{PN})$ did not differ, while intravenous fat from propofol was proportional to the propofol dose and significantly higher in the hyperTG patients (Fig. 1). The correlation between lipid intake and TG levels was significant but less than that of propofol.

\section{Discussion}

The present study confirms that hyperTG is very common in critically ill patients, being observed in $45 \%$ of patients requiring at least 4 days of ICU treatment. It takes a few days to develop, seven as a median. The propofol (dose and lipid vehicle) and the infection were the factors showing the strongest association with this metabolic complication. The incidence of hyperTG varies widely in the literature, ranging from 18 to $38 \%[1,2]$. These differences are attributable to the variability of the patient cohorts, the treatments, and the definition of hyperTG, ranging from $>1.7 \mathrm{mmol} / \mathrm{L}$ to $\geq 5.65 \mathrm{mmol} / \mathrm{L}[1$, $2]$. Indeed, the proportion of patients in our cohort presenting values exceeding $5 \mathrm{mmol} / \mathrm{L}$ was only $4.5 \%$.

The observed changes in TG levels were not a unified process, but the conjunction of infection and high-dose propofol (as shown in Fig. 2) was a frequent pattern. Highdose propofol resulted in increased fat delivery. The association between the propofol dose (1 or $2 \%$ ) and the TG concentrations has been previously investigated, but the time relationship has been inconsistent. McLeod et al. 
[25] found a similar association in 30 ICU patients who received exogenous lipids only from propofol over $50 \mathrm{~h}$. HyperTG induced by propofol has mainly two possible causes: the most likely is the fat emulsion vehicle itself, and possibly but less likely the inhibition of metabolism of fatty acids in the mitochondria [26-28] caused by uncoupling of oxidative phosphorylation and energy production [29]. Some authors have reported that hyperTG was not directly associated with the total amount of infused lipids $[1,8]$, which is interesting as the propofol's LCT emulsion is identical to that used for PN [26, 30]. Moreover, Theilen et al. [16] failed to demonstrate the superiority of a LCT/MCT propofol formulation (supposed to reduce the occurrence of hyperTG), suggesting that lipids associated with propofol were not responsible for the TG alterations. However, prolonged administration of propofol, which amounted to $15.9 \%$ of the total fat delivery in our study, may require adjustment of PN or EN to avoid overfeeding during propofol sedation [31]. From a metabolic point of view it is important to be aware that a very common $200 \mathrm{mg} / \mathrm{h}$ propofol sedation rate (i.e., $4,800 \mathrm{mg}$ of propofol $/ 24 \mathrm{~h}$ ) results in the delivery of $24 \mathrm{~g}$ of fat with a $2 \%$ solution, and $48 \mathrm{~g}$ with a $1 \%$ solution. Importantly, as our ICU uses two different concentrations, there is a slight variation of the propofol-related lipid intake, explaining the stronger correlation with propofol, directly followed by the lipid dose.

Parenteral lipid intake is known to exacerbate hyperTG during acute illness $[2,6]$. Guidelines for parenteral fat intake [13] were respected. Enteral fat is efficiently absorbed, and high doses might alter the lipid profile in case of long-term EN [32], but no association with hyperTG was observed in our cohort. This is probably explained by the use in our hospital of MCT/LCT-based EN solutions, reducing its impact on TG. Our data confirm that hyperTG does not occur when maximal nutritional lipid intakes are respected, the propofol remaining a specific determinant of hyperTG. Among lipids, MCT-containing emulsions seem to be associated with less hyperTG [2, 33], although this remains controversial [14]; as the number of patients on MCT-propofol was low, we could not confirm such a benefit.

Overfeeding by any route with glucose or/and fat is a common cause of hyperTG [34], which was not observed in our cohort where overfeeding was an exception. All patients were monitored daily to prevent overfeeding, and the energy target was frequently verified by indirect calorimetry. Our CIS shows the cumulated glucose dose from both enteral and intravenous routes, thereby enabling avoidance of exceeding the maximal oxidation capacity of $5 \mathrm{mg} / \mathrm{kg} / \mathrm{h}$ [13] and the risk of de novo lipid synthesis [35].

The strong association of TG values with CRP confirms that the acute-phase response causes significant changes to the lipid metabolism [25]. Infection was present in $75.8 \%$ of the patients at the time of hyperTG; the conjunction of an inflammatory response with an elevated propofol dose seems to increase the risk of developing hyperTG.

There was no increase in mortality with hyperTG, but with modest hyperTG (only ten patients had values $>5 \mathrm{mmol} / \mathrm{L}$ ) the impact on outcome is uncertain. Currently, clinical consequences of acute and transient hyperTG remain poorly known, although cases of acute pancreatitis, fatty liver, delayed awakening, retinal lipemia $[2,6,8]$, and elevated mortality particularly in association with hypocholesterolemia [36] have been described. An increased risk of infection by disruption of the reticuloendothelial system [2, 33], coagulopathy [25], neurological disturbance or respiratory failure [2] have also been reported, none of which occurred in our patients.

Seventy patients (32\%) were on statins: hyperTG was as frequent in these patients as in those without. They had received smaller doses of propofol, and importantly they suffered significantly fewer infectious episodes $(p=0.0023)$. At a smaller scale these data are in line with the results of a recent case-control study including 7,223 cases of pneumonia (out of 71,000 hospital admissions) which showed that use of statins decreased pneumonia risk and 30-day mortality [37]. However, the effects of statins on lipid metabolism are pleiotropic, and they are not first-line treatment for hyperTG; absence of impact on TG levels is therefore not surprising.

\section{Limitations of the study}

The principal limitation of this prospective, noninterventional study is the modest size of the cohort, which limits the analysis of the risk factors $(n=220,45 \%$ hyperTG); the low number of patients suffering the predefined risk pathologies precludes drawing strong conclusions. However, the small number of observations has to be weighed against the inclusion of very sick patients with median stay of 10 days and $18.6 \%$ hospital mortality, and the very complete metabolic calculation available in the database. The high proportion of patients receiving the sedative drug propofol nevertheless enables analysis of the impact of this specific drug on the risk of developing hyperTG. With the presence of sepsis, it was the strongest determinant of hyperTG. The most likely explanation is that the other factors have a lesser impact on lipid metabolism in the critically ill.

Another limitation is the wide spectrum of pathologies present in the cohort, and presumably of their genetic characteristics; both modulate the metabolic responses to feeding and to sepsis. In the absence of more information, this aspect cannot be explored. 


\section{Conclusions}

HyperTG is frequent during critical illness, affecting $45 \%$ of the present cohort; TG values remained below $5 \mathrm{mmol} / \mathrm{L}$ in the majority of the patients. Although this alteration was not associated with any worsening of outcome, the variability of the response justifies monitoring of TG levels in case of propofol sedation, as propofol was the external factor most strongly associated with hyperTG. Propofol may be a surrogate though, and this study could not establish whether it was the drug itself or the lipid vehicle that favored
hyperTG. The simultaneous presence of an infection reinforced the TG increase, confirming the impact of the acute-phase response on lipid metabolism. On the other hand, moderate nutritional fat intakes (enteral or parenteral) do not cause this alteration. The TG levels of patients sedated with propofol should therefore be regularly monitored, probably two to three times weekly. Finally, the role of propofol should be further investigated, and clinical consequences of hyperTG remain to be established.

Conflicts of interest None.

\section{References}

1. Barrientos-Vega R, Mar Sanchez-Soria M, Morales-Garcia C, Robas-Gomez A, Cuena-Boy R, Ayensa-Rincon A (1997) Prolonged sedation of critically ill patients with midazolam or propofol: impact on weaning and costs. Crit Care Med 25:33-40

2. Marik PE (2006) Dyslipidemia in the critically ill. Crit Care Clin 22:151-159 viii

3. Mantel-Teeuwisse AK, Kloosterman JME, Maitland-van der Zee AH, Klungel OH, Porsius AJ, de Boer A (2001) Drug-induced lipid changes: a review of the unintended effects of some commonly used drugs on serum lipid levels. Drug Saf 24:443-456

4. Maxime V, Annane D (2005) Manifestations endocriniennes liées au sepsis. Réanimation 14:230-237

5. Bézie Y, Cattan V, Fractal LP, Lescol LP (2003) Comparaison des différentes statines: implications cliniques et choix thérapeutiques. MT Cardio 1:46-54

6. Crook MA (2000) Lipid clearance and total parenteral nutrition: the importance of monitoring plasma lipids. Nutrition 16:774-775

7. Shams MR, Tavassoli N, Plicaud H, Genestal M (2009) Incidence and risk factors of hypertriglyceridemia in the ICU. Crit Care Med 13:130

8. Llop J, Sabin P, Garau M, Burgos R, Perez M, Masso J, Cardona D, Sanchez Segura JM, Garriga R, Redondo S, Sagales M, Ferrer D, Pons M, Vuelta M, Fabregas X, Vitales M, Casasin T, Martinez J, Morato L, Soler M (2003) The importance of clinical factors in parenteral nutrition-associated hypertriglyceridemia. Clin Nutr 22:577-583
9. Firmann M, Mayor V, Vidal PM, Bochud M, Pecoud A, Hayoz D, Paccaud F, Preisig M, Song KS, Yuan $X$, Danoff TM, Stirnadel HA, Waterworth D, Mooser V, Waeber G, Vollenweider P (2008) The CoLaus study: a population-based study to investigate the epidemiology and genetic determinants of cardiovascular risk factors and metabolic syndrome. BMC Cardiovasc Disord 8:6

10. Mesotten D, Swinnen JV, Vanderhoydonc F, Wouters PJ, Van den Berghe G (2004) Contribution of circulating lipids to the improved outcome of critical illness by glycemic control with intensive insulin therapy. J Clin Endocrinol Metabol 89:219-226

11. Vergès B (2007) Physiopathologie de la dyslipidémie du syndrome métabolique et du diabète de type 2 . Nut Clin Metabol 21:9-16

12. Chien JY, Jerng JS, Yu CJ, Yang PC (2005) Low serum level of high-density lipoprotein cholesterol is a poor prognostic factor for severe sepsis. Crit Care Med 33:1688

13. Singer $P$, Berger MM, Van den Berghe G, Biolo G, Calder P, Forbes A, Griffiths R, Kreyman G, Leverve X, Pichard C, ESPEN (2009) ESPEN guidelines on parenteral nutrition: intensive care. Clin Nutr 28:387-400

14. Druml W, Fischer M, Pidlich J, Lenz K (1995) Fat elimination in chronic hepatic failure: long-chain vs mediumchain triglycerides. Am J Clin Nutr 61:812-817

15. Tanaka S, Miki T, Hsieh ST, Kim JI, Yasumoto T, Taniguchi T, Ishikawa Y, Yokoyama M (2003) A case of severe hyperlipidemia caused by long-term tube feedings. J Atheroscler Thromb $10: 321-324$
16. Theilen HJ, Adam S, Albrecht MD, Ragaller M (2002) Propofol in a medium- and long-chain triglyceride emulsion: pharmacological characteristics and potential beneficial effects. Anesth Analg 95:923-929 (table of contents)

17. Al Riyami NB, Frohlich J (2008) Extreme hypertriglyceridemia following intravenous heparin infusion. Clin Biochem 41:907-909

18. Nasstrom B, Olivecrona G, Olivecrona T, Stegmayr BG (2001) Lipoprotein lipase during continuous heparin infusion: tissue stores become partially depleted. J Lab Clin Med 138:206-213

19. Que YA, Bracco D, Chioléro RL (2007) Aspects métaboliques et nutritionnels des catécholamines et des glucocortioïdesTraité de nutrition artificielle de l'adulte. Springer, Berlin, pp 183-191

20. Gibbons RJ, Abrams J, Chatterjee K, Daley J, Deedwania PC, Douglas JS, Ferguson TB Jr, Fihn SD, Fraker TD Jr, Gardin JM (2003) ACC/AHA 2002 guideline update for the management of patients with chronic stable anginasummary article: a report of the American College of Cardiology/ American Heart Association Task Force on practice guidelines (Committee on the Management of Patients With Chronic Stable Angina). J Am Coll Cardiol 41:159

21. Calandra T, Cohen J (2005) The international sepsis forum consensus conference on definitions of infection in the intensive care unit. Crit Care Med 33:1538 
22. Berger MM, Revelly JP, Wasserfallen JB, Schmid A, Bouvry S, Cayeux MC, Musset M, Maravic P, Chiolero RL (2006) Impact of a computerized information system on quality of nutritional support in the ICU. Nutrition 22:221-229

23. Soguel L, Revelly JP, Schaller MD, Longchamp C, Berger MM (2012) Energy deficit and length of hospital stay can be reduced by a two-step quality improvement of nutrition therapy: The intensive care unit dietitian can make the difference. Crit Care Med 40:412

24. Armitage P, Berry G, Matthews JNS (2002) Statistical methods in medical research. Wiley, London

25. McLeod G, Dick J, Wallis C, Patterson A, Cox C, Colvin J (1997) Propofol $2 \%$ in critically ill patients: effect on lipids. Crit Care Med 25:1976-1981

26. Baker MT, Naguib M (2005) Propofol: the challenges of formulation. Anesthesiology 103:860-876

27. Cremer OL (2009) The propofol infusion syndrome: more puzzling evidence on a complex and poorly characterized disorder. Crit Care 13:1012
28. Devlin JW, Mallow-Corbett S, Riker RR (2010) Adverse drug events associated with the use of analgesics, sedatives, and antipsychotics in the intensive care unit. Crit Care Med 38:S231

29. Vasile B, Rasulo F, Candiani A, Latronico N (2003) The pathophysiology of propofol infusion syndrome: a simple name for a complex syndrome. Intensive Care Med 29:1417-1425

30. Devlin JW, Lau AK, Tanios MA (2005) Propofol-associated hypertriglyceridemia and pancreatitis in the intensive care unit: an analysis of frequency and risk factors. Pharmacotherapy 25:1348-1352

31. Roth MS, Martin AB, Katz JA (1997) Nutritional implications of prolonged propofol use. Am J Health Syst Pharm (AJHP) 54:694

32. Petit V, Niot I, Poirier H, Besnard P (2007) Absorption intestinale des acides gras: faits et incertitudes. Nut Clin Metabol 21:38-45

33. Chambrier C, Lauverjat M, Bouletreau $P$ (2006) Emulsions lipidiques: indication des différentes émulsions lipidiques. Nut Clin Metabol 20:73-78
34. Nordenstrom J, Carpentier YA, Askanazi J, Robin AP, Elwyn DH, Hensle TW, Kinney JM (1982) Metabolic utilization of intravenous fat emulsion during total parenteral nutrition. Ann Surg 196:221-231

35. Tappy L, Berger MM, Schwarz JM, Schneiter P, Kim S, Revelly JP, Chiolero R (2006) Metabolic effects of parenteral nutrition enriched with n-3 polyunsaturated fatty acids in critically ill patients. Clin Nutr 25:588-595

36. Chiarla C, Giovannini I, Giuliante F, Zadak Z, Vellone M, Ardito F, Clemente G, Murazio M, Nuzzo G (2010) Severe hypocholesterolemia in surgical patients, sepsis, and critical illness. J Crit Care 25:361.e7-361.e12

37. Nielsen A, Nielsen R, Riis A, Johnsen S, Sorensen H, Thomsen R (2012) The impact of statin use on pneumonia risk and outcome: a combined populationbased case-control and cohort study. Crit Care 16:R122 